\title{
Análise do perfil das publicações sobre alianças estratégicas entre organizações de 2005 à 2015
}

\author{
Sara da Costa Fernandes ${ }^{1}$; Vagner Rosalem ${ }^{2}$
}

\section{Resumo}

As estratégias de parceria e alianças estratégicas entre as organizações são necessidades do processo de sobrevivência e desenvolvimento empresarial diante das exigências do mercado globalizado. $O$ avanço cientifico e pesquisas sobre $o$ tema alianças estratégicas se torna importante para compreender os estudos práticos nas organizações brasileiras. Este estudo através do levantamento bibliográfico teve como objetivo, identificar o perfil dos artigos científicos publicados na base de dados Scielo sobre alianças estratégicas em organizações, entre os anos de 2005 e 2015. A pesquisa é caracterizada como abordagem quantitativa com objetivo exploratório e descritivo. A amostragem foi realizada considerando o descritor "alianças estratégicas" utilizando a análise documental e análise de conteúdo. A partir da pesquisa realizada na base de dados Scielo Brasil, foram encontrados um total de 59 artigos sobre o tema alianças estratégicas. Considerando o período de análise, o idioma e o tipo de estudo feito com aplicabilidade nas organizações brasileiras, foram analisados um total de 24 artigos. Após leitura, identificou-se que 14 artigos poderiam ser base deste estudo.

Palavras Chaves: alianças estratégicas; organizações; perfil dos artigos.

1 Mestranda em Gestão Organizacional pela Universidade Federal de Goiás (UFG), Campus Catalão/GO - Brasil, bolsista da Fundação de Amparo à Pesquisa do Estado de Goiás - FAPEG. Email:sara.scf1@gmail.com

2 Docente na Universidade Federal de Goiás (UFG), Campus Catalão/GO - Brasil, nos cursos de graduação e pós-graduação. Doutor em Administração de Empresas pela Escola de Administração de Empresas de São Paulo da Fundação Getúlio Vargas - EAESP/FGV, Brasil. E-mail: vagner@hotmail.com 


\section{Introdução}

A cada ano, a economia capitalista transforma o cenário empresarial ditando as novas tendências do mercado. As organizações passam a atuar em um mercado dinâmico, marcado pelo continuo processo de globalização, exigindo conquistas de vantagens competitivas e sobrevivência (SOUZA; BALDIM, 2006). Neste sentido, as organizações conquistam e sustentam a vantagem competitiva, quando adotam uma estratégia que considera os fatores básicos que determinam o que a organização pode realizar com sucesso enfrentando as forças competitivas do setor ao desenvolver atividades diferenciadas e atrativas (PORTER, 1999).

As estratégias de cooperação e parceria entre organizações segundo Lorange; Ross (1996) são consideradas fenômenos próprios do processo de adaptação, sobrevivência e desenvolvimento empresarial diante as exigências do mercado. Dentre as estratégias cooperação e parceria adotadas pelas organizações, tais como contratos de longo prazo, licenciamento, franquias e terceirização Mintzberg; Ahlstrand; Lampel, (2010), abordam as alianças estratégicas como forma de resposta à crescente evolução da tecnologia, necessidade de acesso a novos recursos e a adequação as mudanças no ambiente econômico.

Para Galerani (2003), as alianças estratégicas trazem vantagens às organizações como a redução de custos, otimização de investimentos, melhoria nas técnicas de gestão, flexibilidade, desenvolvimento da inovação e fortalecimento no mercado. Além disto, as alianças estratégicas se desenvolvem e se propagam constituindo arranjos cooperativos organizacionais na busca de objetivos que envolvem maior grau de colaboração entre organizações (TODEVA; KNOKE, 2005). No entanto, as alianças como estratégias empresariais são uma forma diferenciada de coordenação da atividade econômica em que as partes individuais de cada organização existem não por si mesmas, mas pelas relações com as outras (ROSALEM, 2007).

A esse respeito, Mattana; Noro; Estrada (2008), afirmam serem relevantes as pesquisas sobre análise do processo de formação e gestão no estabelecimento de alianças estratégicas. $\mathrm{O}$ avanço científico sobre o tema alianças estratégicas deriva do conhecimento disponível sobre ele, sendo resultado de investigações entre pesquisadores ao longo do tempo. Conhecer a evolução das principais correntes teóricas, alguns estudiosos e a produção acadêmica de maior relevância podem colaborar de forma significativa para melhor compreensão dos estudos existentes e identificação de problemas práticos nas organizações (MORAN et al., 2010). De modo geral, os estudos sobre o tema têm o objetivo de investigar como ocorre o processo de formação e gestão de alianças estratégicas por organizações do mercado (KLEIN, 2012).

Diante do exposto, o objetivo principal do presente trabalho é através do levantamento bibliográfico, identificar o perfil dos artigos científicos publicados na base de dados Scielo sobre alianças estratégicas em organizações, entre os anos de 2005 e 2015. Ressalta-se que a opção pela análise das publicações da base de dados Scielo justifica-se por ser uma biblioteca eletrônica livre e de fácil acesso, que abrande uma coleção selecionada de periódicos científicos brasileiros. Para alcançar este objetivo buscou-se identificar os objetivos e características dos artigos publicados, o segmento das organizações pesquisadas, o ano de publicação, os periódicos, o tipo de pesquisa realizada e o método de coleta de dados. 
A relevância do presente trabalho pauta-se pelo interesse em identificar e compreender o perfil das principais correntes teóricas sobre alianças estratégicas, suas intensidades de publicações já realizadas sobre o tema e sua aplicabilidade em algumas organizações brasileiras. Neste contexto torna-se oportuno a utilização da pesquisa bibliográfica como técnica de análise associando à importância e qualidade dos resultados.

\section{Desenvolvimento}

\subsection{Estratégias Organizacionais}

A globalização, a concorrência e os fatores do ambiente externo como a instabilidade econômica dos últimos tempos, têm levado as organizações a estudarem as melhores formas de sobrevivência em um mercado cada dia mais estratégico. Deste modo, ao estabelecerem estratégias de sobrevivência e crescimento, as organizações atuam em posições de negócios em diferentes meios e diferentes abordagens (THOMPSON; STRICKLAND, 2001).

De acordo com Rumelt (2011), a ideia de estratégia é fazer a aplicação dos pontos fortes contra os pontos fracos. Para Hitt; Ireland; Hoskisson (2011) a estratégia é "um conjunto integrado e coordenado de compromissos e ações definidos para explorar competências essenciais e obter vantagem competitiva" ( $p$. 4).

A estratégia organizacional estabelece ações que orientam a organização na direção que se pretende seguir. Uma estratégia inclui a definição e abrangência do produto, as necessidades de investimentos e recursos, bem como os ativos ou competências a serem empregados (AAKER; KUMAR; DAY, 2001). Porter (1999, p. 63) define que estratégia é "a capacidade de criar uma posição exclusiva e valiosa, envolvendo um diferente conjunto de atividades".

Para Wright; Kroll; Parnell (2000, p. 132), as estratégias podem ser definidas nos seguintes tipos: estratégia de crescimento, estabilidade ou redução. Para a estratégia de crescimento, as opções existentes são o crescimento interno, integração horizontal, diversificação horizontal, integração vertical, fusões e alianças estratégicas. As estratégias de estabilidade ou redução estão o desinvestimento e liquidação. A partir de Wright; Kroll; Parnell (2000), Façanha (2012), apresentou em seu estudo o quadro resumo com as principais características, vantagens e desvantagens das estratégias conforme mostra a Figura 1. 
Figura 1: Alternativas de Estratégias de Crescimento

\begin{tabular}{|c|c|c|c|}
\hline Estratégia & Características & Vantagens & Desvantagens \\
\hline $\begin{array}{l}\text { Crescimento } \\
\text { Interno }\end{array}$ & $\begin{array}{l}\text { Crescimento orgânico no } \\
\text { mesmo negócio ou em } \\
\text { novos negócios, de forma } \\
\text { horizontal ou vertical. }\end{array}$ & $\begin{array}{l}\text { Preserva a cultura, a } \\
\text { eficiência, a qualidade e a } \\
\text { imagem da organização. }\end{array}$ & $\begin{array}{l}\text { Aumento dos } \text { custos } \\
\text { burocráticos e de } \\
\text { coordenação. }\end{array}$ \\
\hline $\begin{array}{l}\text { Integração } \\
\text { Horizontal }\end{array}$ & $\begin{array}{l}\text { Expansão por intermédio de } \\
\text { aquisição de outras } \\
\text { empresas na mesma linha de } \\
\text { negócios }\end{array}$ & $\begin{array}{l}\text { Aumento da participação do } \\
\text { mercado, maior poder de } \\
\text { alavancagem para lidar com } \\
\text { fornecedores e clientes e } \\
\text { maior flexibilidade } \\
\text { operacional. }\end{array}$ & $\begin{array}{l}\text { Eventuais problemas } \\
\text { relacionados com a } \\
\text { legislação antitruste. }\end{array}$ \\
\hline $\begin{array}{l}\text { Diversificação } \\
\text { Horizontal } \\
\text { Relacionada }\end{array}$ & $\begin{array}{l}\text { Aquisição de uma empresa } \\
\text { de um setor externo ao atual } \\
\text { campo de atuação, mas com } \\
\text { competências essenciais } \\
\text { semelhantes } \\
\text { complementares. }\end{array}$ & $\begin{array}{l}\text { Sinergia (economias e/ou } \\
\text { inovações de escopo } \\
\text { horizontal) e fortalecimento } \\
\text { das competências essenciais }\end{array}$ & $\begin{array}{l}\text { Aumento dos custos } \\
\text { burocráticos e maiores } \\
\text { custos de coordenação } \\
\text { das várias unidades de } \\
\text { negócio. }\end{array}$ \\
\hline $\begin{array}{l}\text { Integração } \\
\text { Horizontal Não } \\
\text { relacionada } \\
\text { (conglomerados) }\end{array}$ & $\begin{array}{l}\text { Aquisição de uma empresa } \\
\text { de um setor externo ao atual } \\
\text { campo de atuação, sem } \\
\text { competências essenciais } \\
\text { semelhantes } \\
\text { complementares. }\end{array}$ & $\begin{array}{l}\text { Alavancagem } \\
\text { predominantemente } \\
\text { financeira, mas com baixos } \\
\text { custos de coordenação, } \\
\text { visto que a empresa } \\
\text { adquirida permanece } \\
\text { independente. }\end{array}$ & $\begin{array}{l}\text { Aumento dos custos } \\
\text { burocráticos. }\end{array}$ \\
\hline $\begin{array}{l}\text { Integração } \\
\text { Vertical } \\
\text { Relacionada }\end{array}$ & $\begin{array}{l}\text { União de vários estágios das } \\
\text { atividades da cadeia de } \\
\text { suprimentos seja de forma } \\
\text { regressiva (fornecedores) ou } \\
\text { progressiva (clientes); } \\
\text { parcial ou integral; com } \\
\text { compartilhamento e/ou } \\
\text { transferência de } \\
\text { competências essenciais } \\
\text { e/ou complementares. }\end{array}$ & $\begin{array}{l}\text { Economias de cadeia } \\
\text { vertical e/ou horizontal, } \\
\text { economias de escopo } \\
\text { horizontal, inovações na } \\
\text { cadeia vertical ou } \\
\text { combinação de economias e } \\
\text { inovação na cadeia vertical. }\end{array}$ & $\begin{array}{l}\text { Tendência a não } \\
\text { capitalizar potenciais de } \\
\text { eficiência e inovação } \\
\text { desenvolvidos no } \\
\text { ambiente externo }\end{array}$ \\
\hline $\begin{array}{l}\text { Integração } \\
\text { Vertical Não- } \\
\text { Relacionada }\end{array}$ & $\begin{array}{l}\text { Possibilidades limitadas de } \\
\text { transferência e/ou } \\
\text { compartilhamento de } \\
\text { competências essenciais } \\
\text { e/ou complementares. }\end{array}$ & $\begin{array}{l}\text { Tendem a adotar melhorias } \\
\text { e inovações externas, logo - } \\
\text { em ambientes dinâmicos - } \\
\text { enfrentam menor risco de } \\
\text { obsolescência tecnológica. }\end{array}$ & $\begin{array}{l}\text { Altos custos de } \\
\text { burocracia e riscos de } \\
\text { custos mais altos em } \\
\text { função da não procura } \\
\text { de propostas } \\
\text { competitivas junto a } \\
\text { competidores externos. }\end{array}$ \\
\hline Fusão & $\begin{array}{l}\text { Ocorre quando duas ou mais } \\
\text { empresas combinam-se em } \\
\text { outra empresa por meio de } \\
\text { permuta de ações. }\end{array}$ & $\begin{array}{l}\text { Sinergia (maior eficácia e } \\
\text { eficiência resultante da } \\
\text { fusão, em relação às } \\
\text { empresas separadas). }\end{array}$ & $\begin{array}{l}\text { Maiores } \\
\text { burocráticos eustos } \\
\text { aquisição. }\end{array}$ \\
\hline $\begin{array}{l}\text { Alianças } \\
\text { Estratégicas } \\
\text { (Joint Ventures, } \\
\text { franquias, } \\
\text { licenciamento, } \\
\text { etc.). }\end{array}$ & $\begin{array}{l}\text { Parcerias em que duas ou } \\
\text { mais empresas realizam um } \\
\text { projeto específico ou } \\
\text { cooperam em determinada } \\
\text { área de negócio. Podem ser } \\
\text { temporárias ou de longo } \\
\text { prazo. }\end{array}$ & $\begin{array}{llr}\begin{array}{l}\text { Pouco aumento } \\
\text { burocráticos de }\end{array} & \text { custos } \\
\text { coordenação } & \text { e } & \text { riscos } \\
\text { reduzidos. } & & \end{array}$ & $\begin{array}{l}\text { Desequilibrio } r \text { entre } \\
\text { parceiros da aliança } \\
\text { estratégica pode gerar } \\
\text { resultados aquém dos } \\
\text { esperados. }\end{array}$ \\
\hline
\end{tabular}

Fonte: Façanha (2012) a partir de Wright; Kroll; Parnell (2000).

As estratégias organizacionais são formadas pela alta administração da organização composto por diretores e gerentes. Logo, são direcionadas aos funcionários para alcançar os objetivos globais da organização que desenvolvem a partir de suas atividades as estratégias definidas visando contribuir com o sucesso organizacional (CERTO; PETERS, 2005). Child; Faulker (1998), propuseram uma matriz demonstrada na Figura 2, partindo de duas dimensões estratégicas: a importância da atividade e a competência da atividade comparada com a considerada melhor organização do mercado. 
Figura 2: Recomendações estratégicas

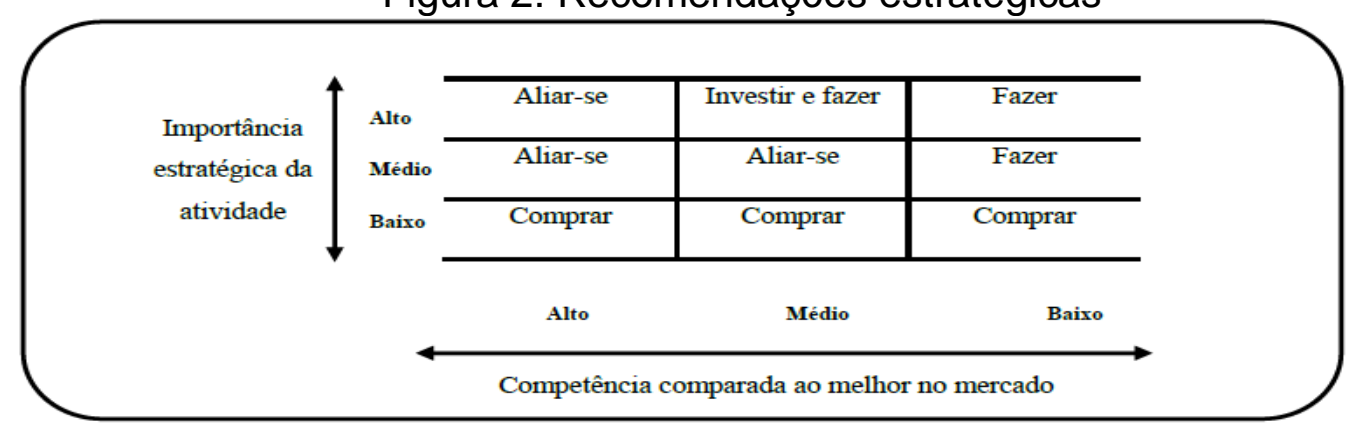

Fonte: Child; Faulker (1998).

A seguir serão apresentados os principais conceitos sobre alianças estratégicas como forma de expansão e desenvolvimento das organizações no mercado atual.

\subsection{Alianças Estratégicas}

As alianças estratégicas consistem em uma alternativa usual para viabilizar acordos de cooperação e são respostas estratégicas aos principais desafios ou oportunidades que as organizações enfrentam no ambiente de negócios (FAÇANHA, 2012). Nesta perspectiva, as alianças estratégicas emergem como instrumento de uma gestão inovadora, apoiada na expansão, compartilhando recursos e se tornando mais competitivas (KANTER, 1996).

Neste contexto, as organizações adotam alianças estratégicas como forma de se desenvolverem no mercado. Abbade (2009) considera que as alianças estratégicas representam um meio de as organizações aumentarem sua competitividade visto o ambiente cada dia mais turbulento e menos acessível. A cooperação entre organizações é uma estratégia necessária para sobreviver no atual contexto de globalização e competitividade.

Importantes autores da literatura sobre alianças estratégicas, Lorange; Ross (1996), afirmam que as organizações que fazem cooperação, alianças e parcerias procuram se adaptarem, sobreviverem e se desenvolverem em relação as exigências de mercado. As operações quanto mais voltadas para a direita, mais integrada as organizações estão. A integração vertical pode ser interpretada como uma "combinação de processos de produção, distribuição, vendas ou outros processos econômicos distintos dentro das fronteiras de uma mesma organização" (PORTER, 1999, p. 278).

Para Yoshino; Rangan (1996, p.5), a aliança estratégica é "uma parceria comercial que aumenta a eficácia das estratégias competitivas das organizações participantes, propiciando o intercambio mútuo e benéfico de tecnologias, qualificações ou produtos baseados nesta". Os autores ainda argumentam que as organizações podem permanecer independentes após a formação da aliança para alcançar metas conjuntas estabelecidas; as organizações se aliam na busca de objetivos comuns e compartilham os benefícios obtidos através da aliança; há uma contribuição continua entre as organizações parceiras em áreas estratégicas como tecnologias, produtos e outros.

Child; Faulker (1998), argumentam que as alianças estratégicas estão relacionadas a cadeia de valor da organização, pois as parcerias podem reunir 
competências similares ou complementares. A reunião de competências similares são alianças em que o interesse principal das organizações é gerar economias de escopo e participação no mercado. Já as complementares são alianças em que as organizações contribuem com diferentes atividades ou produtos da cadeia de valor.

Neste sentido, a formação de alianças estratégicas são respostas aos fatores ambientais, aos aspectos relativos a globalização como queda de barreiras internacionais, tecnologias, economias de escala e escopo considerando habilidades e competências, a participação de mercado e a cultura organizacional (HAGEDOORN; SCHAKENRAAD, 1994). A colaboração entre organizações potencializa as forças de cada uma para que alcancem seus objetivos estratégicos através de um compromisso de longo prazo (AAKER; KUMAR; DAY, 2001).

As alianças consistem em estratégias que levam ao mercado as organizações que de forma separada não conseguiriam ir. Trata-se também do desenvolvimento de novos produtos ou serviços que uma organização sozinha não conseguiria desenvolver (CARTER; CUSHIMAN; HARTZ, 1988). De Man (2005) adiciona que, as alianças estratégicas são acordos de cooperação em que as organizações se unem para compartilhar recursos em busca de desenvolvimento.

Neste contexto para compreender os estudos acerca do tema alianças estratégicas aplicadas nas organizações, as sessões a seguir apresentarão o perfil das principais correntes teóricas e suas intensidades de publicações. Trata-se de um assunto relevante cada vez mais comum na realidade das organizações brasileiras.

\subsection{Metodologia}

Quanto aos objetivos o presente estudo é caracterizado como exploratório e descritivo. As pesquisas exploratórias "tem como objetivo principal o aprimoramento de idéias ou a descoberta de intuições" (GIL, 2002, p. 41). As pesquisas descritivas "tem como objetivo primordial a descrição das características de determinada população ou fenômeno, ou então, o estabelecimento de relações entre as variáveis" (GIL, 2002, p. 42). Trata-se de explorar e descrever os estudos sobre o tema alianças estratégicas nas organizações brasileiras indexado na base de dados Scielo entre 2005 e 2015.

A pesquisa foi realizada utilizando a base de dados Scielo (Scientific Electronic Library Online), pois é uma biblioteca eletrônica livre e de fácil acesso, que abrande uma coleção selecionada de periódicos científicos brasileiros. É o resultado de um projeto de pesquisa da FAPESP (Fundação de Amparo a Pesquisa do Estado de São Paulo) em pareceria com a BIREME (Centro Latino-Americano e do Caribe de Informação em Ciências da Saúde) e conta com o apoio do CNPq (Conselho Nacional de Desenvolvimento Científico e Tecnológico) (SCIELO, 2016).

Nesta perspectiva, o estudo foi realizado a partir de uma pesquisa bibliográfica, que para Vergara (2009) constitui um estudo sistematizado desenvolvido a partir de material publicado em livros ou rede eletrônica. Nesta perspectiva a pesquisa bibliográfica foi utilizada para conhecer as principais correntes teóricas sobre alianças estratégicas, suas intensidades de publicações já realizadas sobre o tema e sua aplicabilidade em algumas organizações brasileiras.

A abordagem é quantitativa, pois "caracteriza-se pelo emprego da quantificação tanto nas modalidades de coleta de informações, quanto no tratamento dessas através de técnicas estatísticas" (RICHARDSON, 1999 p. 70). A população do estudo compreendeu os artigos publicados na base de dados Scielo entre 2005 e 
2015 sobre o tema alianças estratégicas aplicadas em organizações brasileiras. Foi realizada a tabulação de dados através de planilhas eletrônicas do sofware Microsoft Office Excel 2007.

A amostragem foi feita considerando o descritor "alianças estratégicas", utilizando os critérios de inclusão os artigos: publicados entre 2005 e 2015, disponíveis na íntegra, abordagem organizacional, em idioma português, estudos aplicados em organizações brasileiras nas áreas temáticas ciências sociais e engenharia. As categorias de análise foram: os objetivos e características dos artigos publicados, o ano de publicação, os periódicos, o tipo de pesquisa realizada, o método da coleta de dados e o segmento das organizações pesquisadas.

Para análise de dados foi utilizado a análise documental e análise de conteúdo. O uso de documentos é uma importante fonte de evidências que visam representar o conteúdo de um documento (BARDIN, 2009). A análise de conteúdo para Bardin (2009) refere-se a um conjunto de técnicas de analise de comunicação que dispõe informação por meio de uma fonte documental, permitindo gerar conhecimentos da produção de mensagens por meio de procedimentos que descrevem o conteúdo dos documentos analisados.

Assim, através pesquisa bibliográfica utilizando a base de dados Scielo, foram analisados os artigos sobre o tema alianças estratégicas, onde identificou o perfil das principais correntes teóricas sobre o tema a partir da tabulação e interpretação dos dados disponíveis.

\subsection{Análise dos Resultados}

Para Moran et. al (2010) o avanço científico sobre o tema alianças estratégicas é resultado do conhecimento já disponível sobre ele através de estudos de outros pesquisadores ao longo do tempo. Segundo os autores, é relevante conhecer a evolução dos conceitos, estudiosos e produções acadêmicas para que ocorra uma melhor compreensão da teoria existente.

A partir da pesquisa realizada na base de dados Scielo Brasil, foram encontrados um total de 59 artigos sobre o tema alianças estratégicas. Considerando o período de análise, o idioma e o tipo de estudo feito com aplicabilidade nas organizações brasileiras, foram analisados um total de 24 artigos. Após leitura, identificou-se que 14 artigos poderiam ser base deste estudo, onde 10 artigos foram excluídos, pois não estavam atendendo a temática em ciências sociais e engenharias com aplicabilidade nas organizações. Considerando isto e baseado na pesquisa de Lima et. al (2015), o Quadro 1 abaixo apresenta título, autores, objetivos/características e método de análise de dados dos artigos considerados.

Quadro 1: Características dos artigos

\begin{tabular}{|l|l|l|}
\hline \multicolumn{1}{|c|}{ Título } & \multicolumn{1}{|c|}{ Assunto/Objetivo } & \multicolumn{1}{c|}{ Análise de Dados } \\
\hline $\begin{array}{l}\text { Alinhamento estratégico da } \\
\text { responsabilidade socioambiental } \\
\text { corporativa em empresas que atuam em } \\
\text { redes de relacionamento: resultados de } \\
\text { pesquisa na Petrobrás }\end{array}$ & $\begin{array}{l}\text { Investigou o impacto das } \\
\text { alianças estratégicas e redes } \\
\text { de relacionamento na gestão } \\
\text { da Petrobrás considerando a } \\
\text { dimensão socioambiental. }\end{array}$ & $\begin{array}{l}\text { Análise documental, } \\
\text { questionários } \\
\text { estruturados e } \\
\text { entrevistas. }\end{array}$ \\
VOLPON; SOARES (2007) & & \\
\hline
\end{tabular}




\begin{tabular}{|c|c|c|}
\hline $\begin{array}{l}\text { Alianças estratégicas no setor de } \\
\text { autopeças: o caso } \\
\text { Forjas brasileiro } \\
\text { CELARO; SOARES (2007) }\end{array}$ & $\begin{array}{l}\text { Contribuiu com os estudos } \\
\text { sobre a gestão das empresas } \\
\text { inseridas em alianças, } \\
\text { focando na questão de suas } \\
\text { implicações estratégicas, à luz } \\
\text { das suas características } \\
\text { relacionais: o caso Forjas } \\
\text { brasileiro. }\end{array}$ & $\begin{array}{l}\text { Análise documental e } \\
\text { telematizada e } \\
\text { questionários }\end{array}$ \\
\hline $\begin{array}{l}\text { Identificação de mecanismos de controle } \\
\text { em alianças estratégicas para } \\
\text { desenvolvimento tecnológico: um estudo } \\
\text { múltiplo de casos no setor metal- } \\
\text { mecânico ao longo das fases de } \\
\text { relacionamento } \\
\text { BOEHS; MENDES (2007) }\end{array}$ & $\begin{array}{l}\text { Identificou os mecanismos de } \\
\text { controle em alianças } \\
\text { estratégicas voltadas para } \\
\text { atividades de desenvolvimento } \\
\text { tecnológico entre empresas do } \\
\text { setor metal-mecânico. }\end{array}$ & $\begin{array}{l}\text { Entrevistas e Análise } \\
\text { documental }\end{array}$ \\
\hline $\begin{array}{l}\text { O lock-in estratégico em relacionamentos } \\
\text { inter-organizacionais: o caso da Dataprev } \\
\text { TINOCO; SOARES (2008) }\end{array}$ & $\begin{array}{l}\text { Descreveu o caso da } \\
\text { Dataprev, uma empresa } \\
\text { pública de serviços de } \\
\text { tecnologia da informação, que } \\
\text { toma a decisão de mudar sua } \\
\text { estratégia em relação à sua } \\
\text { parceria com um fornecedor. }\end{array}$ & $\begin{array}{l}\text { Análise documental e } \\
\text { entrevistas }\end{array}$ \\
\hline $\begin{array}{l}\text { Aliança estratégica no canal de } \\
\text { marketing: o caso ALE Combustíveis } \\
\text { S.A. } \\
\text { COTTA; DALTO }(2010)\end{array}$ & $\begin{array}{l}\text { Analisou da estratégia } \\
\text { utilizada pela ALE } \\
\text { Combustíveis em uma } \\
\text { operação desenhada para } \\
\text { vender lubrificantes } \\
\text { automotivos em sua rede de } \\
\text { postos. }\end{array}$ & $\begin{array}{l}\text { Análise documental, } \\
\text { observação } \\
\text { participante e } \\
\text { entrevistas }\end{array}$ \\
\hline $\begin{array}{l}\text { O modelo de integração de sistemas da } \\
\text { indústria aeronáutica: fatores } \\
\text { motivadores } \\
\text { GUERRA (2011) }\end{array}$ & $\begin{array}{l}\text { Estudou a ampliação das } \\
\text { alianças estratégicas dos } \\
\text { principais fabricantes de avião } \\
\text { do mundo para identificar e } \\
\text { compreender os fatores que } \\
\text { os têm motivado a adotar este } \\
\text { modelo. }\end{array}$ & Análise da Literatura \\
\hline $\begin{array}{l}\text { A convergência recente entre os setores } \\
\text { brasileiros de comunicação de massa e } \\
\text { de telecomunicações } \\
\text { LADEIRA (2011) }\end{array}$ & $\begin{array}{l}\text { Analisou do processo recente } \\
\text { de alianças estratégicas entre } \\
\text { organizações do setor de } \\
\text { telecomunicações e de } \\
\text { comunicação de massa } \\
\text { (especialmente o audiovisual) } \\
\text { ocorrido no Brasil durante a } \\
\text { última década. }\end{array}$ & Análise Documental \\
\hline $\begin{array}{l}\text { DeFábrica, fundo de quintal"a empresa } \\
\text { multinacional: o caso de uma aliança } \\
\text { ítalo-brasileira sob o enfoque da } \\
\text { abordagem estruturacionista da } \\
\text { estratégia como prática } \\
\text { TEIXEIRA; COSTA (2012) }\end{array}$ & $\begin{array}{l}\text { Investigou indícios } \\
\text { estruturacionistas, decorrentes } \\
\text { de uma aliança estratégica } \\
\text { interorganizacional, que } \\
\text { possam ter resultado na } \\
\text { mudança de uma fábrica } \\
\text { fundo de quintal para uma } \\
\text { empresa multinacional. }\end{array}$ & Entrevistas \\
\hline
\end{tabular}




\begin{tabular}{|c|c|c|}
\hline $\begin{array}{l}\text { Alianças estratégicas colaborativas e o } \\
\text { ambiente institucional-regulatório em } \\
\text { empresas de biotecnologia: segmento } \\
\text { saúde humana na região sul do Brasil } \\
\text { FERREIRA JÚNIOR; SEGATTO (2013) }\end{array}$ & $\begin{array}{l}\text { Analisou a relação entre o } \\
\text { ambiente institucional- } \\
\text { regulatório em biotecnologia, } \\
\text { segmento de saúde humana, } \\
\text { e alianças estratégicas } \\
\text { realizadas pelas empresas } \\
\text { deste setor }\end{array}$ & $\begin{array}{l}\text { Entrevistas, } \\
\text { observação não } \\
\text { participante, material } \\
\text { institucional de } \\
\text { divulgação (folders, } \\
\text { panfletos e sítios } \\
\text { eletrônicos) }\end{array}$ \\
\hline $\begin{array}{l}\text { Alianças estratégicas no varejo } \\
\text { farmacêutico: vantagens e desvantagens } \\
\text { na percepção do gestor } \\
\text { RIBEIRO; PRIETO (2013) }\end{array}$ & $\begin{array}{l}\text { Este estudo teve como } \\
\text { objetivo ampliar a } \\
\text { compreensão do movimento } \\
\text { competitivo que tem se } \\
\text { desenvolvido no varejo } \\
\text { farmacêutico. }\end{array}$ & Entrevistas \\
\hline $\begin{array}{l}\text { Para além do olhar econômico nas } \\
\text { alianças estratégicas: implicações } \\
\text { sociológicas do caso Unihotéis } \\
\text { VIZEU; GUARIDO FILHO; GOMES } \\
\text { (2014) }\end{array}$ & $\begin{array}{l}\text { Discutiu o fenômeno das } \\
\text { alianças estratégicas à luz da } \\
\text { perspectiva sociológica de } \\
\text { análise em contraponto com a } \\
\text { orientação econômica no setor } \\
\text { de hotelaria brasileira }\end{array}$ & $\begin{array}{l}\text { Análise documental e } \\
\text { entrevistas }\end{array}$ \\
\hline $\begin{array}{l}\text { As alianças estratégicas no picadeiro da } \\
\text { arte/ negócio circense } \\
\text { QUARESMA JÚNIOR; SILVA; CARRIERI }\end{array}$ & $\begin{array}{l}\text { Estudou a contribuição das } \\
\text { alianças para a longevidade } \\
\text { das empresas, tendo como } \\
\text { objeto um campo quase } \\
\text { esquecido pela administração, } \\
\text { as organizações circenses. }\end{array}$ & $\begin{array}{l}\text { Observações, } \\
\text { entrevistas e análise } \\
\text { documental }\end{array}$ \\
\hline $\begin{array}{l}\text { "O Que Gerencio e de Quem Dependo?”: } \\
\text { Determinantes da Ação de Blogueiros } \\
\text { CASTRO; SANTOS JÚNIOR (2015) }\end{array}$ & $\begin{array}{l}\text { Considerando que os Blogs } \\
\text { são cada vez mais procurados } \\
\text { por empresas para constituir } \\
\text { alianças estratégicas. Foi } \\
\text { desenvolvido um modelo } \\
\text { teórico para caracterizar a } \\
\text { ação gerencial do blogueiro de } \\
\text { acordo com o contexto do } \\
\text { blog. }\end{array}$ & $\begin{array}{l}\text { Questionários e } \\
\text { entrevistas }\end{array}$ \\
\hline $\begin{array}{l}\text { Fatores que influenciaram no } \\
\text { desempenho de alianças estratégicas } \\
\text { firmadas entre empresas do real } \\
\text { estatebrasileiro } \\
\text { CAMARGO; MONETTI; ALENCAR } \\
(2015)\end{array}$ & $\begin{array}{l}\text { Apresentou uma análise } \\
\text { diagnóstica dos principais } \\
\text { fatores de dificuldade que } \\
\text { influenciaram no desempenho } \\
\text { de tais parcerias, assim como } \\
\text { as principais vantagens } \\
\text { identificadas. }\end{array}$ & $\begin{array}{l}\text { Entrevistas e Análise } \\
\text { da literatura }\end{array}$ \\
\hline
\end{tabular}

Fonte: Elaborado pelos Autores

Analisando os objetivos e características dos artigos publicados na base de dados Scielo, identifica-se que foram analisados os fatores e benefícios das alianças estratégicas nas organizações estudadas. Identifica-se a predominância de pesquisas compostas por dois autores e quanto ao método de coleta de dados predominam as entrevistas e análise documental. A partir dos resultados apresentados foram identificadas algumas áreas que referenciam as alianças estratégicas nas organizações envolvidas, como, capacidade de absorção, conhecimento, desempenho, gestão, inovação, redes, pesquisa e desenvolvimento. 
Verschoore et. al (2014) salientam que os estudos sobre o tema alianças estratégicas começaram a expandir em periódicos científicos por volta do ano de 2004. Para os autores, a maioria dos artigos buscam enriquecer o conhecimento sobre cooperação entre organizações aplicados a estudos na área das ciências sociais e engenharias. Foi na primeira década do século XXI que surgiram novas contribuições teóricas e empíricas aplicados em estudos de casos de parcerias entre importantes organizações brasileiras.

O Quadro 2 apresenta a quantidade de publicações sobre alianças estratégicas com aplicabilidade em organizações brasileiras, publicados entre os anos de 2005 a 2015. Identifica-se que entre os anos de 2005 e 2006 e no ano de 2009 não houve um estudo aplicado em organizações, representando uma média de 2 artigos ao ano.

Quadro 2: Quantidade de trabalhos publicados

\begin{tabular}{|c|c|c|}
\hline Ano & Quantidade & Frequência \\
\hline 2007 & 3 & $21 \%$ \\
\hline 2008 & 1 & $7 \%$ \\
\hline 2010 & 1 & $7 \%$ \\
\hline 2011 & 2 & $14 \%$ \\
\hline 2012 & 1 & $7 \%$ \\
\hline 2013 & 2 & $14 \%$ \\
\hline 2014 & 2 & $14 \%$ \\
\hline 2015 & 2 & $14 \%$ \\
\hline Total & 14 & $\mathbf{1 0 0} \%$ \\
\hline
\end{tabular}

Fonte: Elaborado pelos autores

A produção científica e a publicação em periódicos aceitos pela comunidade e por outros pesquisadores tem sido muito incentivada principalmente pelo fato de as pesquisas produzirem e divulgarem conhecimentos (VOLPATO, 2002). Nesta perspectiva, o volume de publicações por periódicos, é demonstrado no Quadro 3, apresentando 9 periódicos de 14 artigos analisados. As revistas com maior volume de periódicos publicados são Gestão \& Produção, RAM - Revista de Administração Mackenzie, Cadernos EBAPE.BR e Revista de Administração Pública. Todas as revistas apresentadas no Quadro 3 abrem espaço para a divulgação de trabalhos na área cientifica de negócios e organizações.

Quadro 3: Periódicos

\begin{tabular}{|l|c|c|}
\hline \multicolumn{1}{|c|}{ Periódicos Publicados } & Quantidade & Frequência \\
\hline Gestão \& Produção & 3 & $\mathbf{2 1 \%}$ \\
\hline RAM - Revista Administração Mackenzie & 2 & $14 \%$ \\
\hline Revista de Administração Contemporânea & 1 & $7 \%$ \\
\hline Cadernos EBAPE.BR & 2 & $14 \%$ \\
\hline Production & 1 & $7 \%$ \\
\hline Revista de Administração Pública & 2 & $14 \%$ \\
\hline Ambiente Construído & 1 & $7 \%$ \\
\hline
\end{tabular}




\begin{tabular}{|c|c|c|}
\hline Intercom: Revista Brasileira de Ciências da Comunicação & 1 & $7 \%$ \\
\hline REAd. Revista Eletrônica de Administração & 1 & $7 \%$ \\
\hline Total & 14 & $\mathbf{1 0 0 \%}$ \\
\hline
\end{tabular}

Fonte: Elaborado pelos autores

Quanto aos procedimentos de pesquisa, Fonseca (2002) afirma que é uma forma de aproximar, investigar e entender a realidade como um processo que permite a intervenção real. Um método de pesquisa é indispensável para alcançar o objetivo e responder a pergunta de pesquisa.

Conforme demonstrado no Quadro 4, no total dos artigos analisados, 6 (43\%) apresentaram o estudo de caso como método de pesquisa, sendo 4 (29\%) o estudo de caso múltiplo. A pesquisa de campo exploratória foi apresentando em $21 \%$ dos casos. Assim identifica-se que a pesquisa sobre alianças estratégicas nas organizações, o método mais utilizado é o estudo de caso. Para Yin (2015) o estudo de caso é um método de pesquisa utilizado em muitas situações que contribuem com o conhecimento dos fenômenos individuais, grupais, organizacionais e sociais.

Quadro 4: Metodologia de pesquisa

\begin{tabular}{|l|c|c|}
\hline \multicolumn{1}{|c|}{ Tipo de Pesquisa } & Quantidade & Frequência \\
\hline Estudo de Caso & 6 & $43 \%$ \\
\hline Estudo de Caso Múltiplo & 4 & $29 \%$ \\
\hline Pesquisa Bibliográfica & 1 & $7 \%$ \\
\hline $\begin{array}{l}\text { Pesquisa de Campo } \\
\text { Exploratória }\end{array}$ & 3 & $21 \%$ \\
\hline \multicolumn{1}{|c|}{ Total } & $\mathbf{1 4}$ & $\mathbf{1 0 0 \%}$ \\
\hline
\end{tabular}

Fonte: Elaborado pelos autores

Quanto ao segmento das organizações pesquisadas verificou-se que estão bem divididas entre os 14 artigos analisados. Conforme demonstrado no Quadro 5, o segmento de petróleo/combustíveis foi o mais estudado. A frequência foi a mesma para os demais segmentos.

Quadro 5: Segmento das organizações pesquisadas

\begin{tabular}{|l|c|c|}
\hline \multicolumn{1}{|c|}{ Segmento Organizações Pesquisadas } & Quantidade & Frequência \\
\hline Petróleo/combustíveis & 2 & $14 \%$ \\
\hline Autopeças & 1 & $7 \%$ \\
\hline Metalúrgico & 1 & $7 \%$ \\
\hline Teconologia da Informação & 1 & $7 \%$ \\
\hline Aeronáutica & 1 & $7 \%$ \\
\hline Telecomunicações & 1 & $7 \%$ \\
\hline Móveis & 1 & $7 \%$ \\
\hline Biotecnologia & 1 & $7 \%$ \\
\hline Farmacêutico & 1 & $7 \%$ \\
\hline Hotelaria & 1 & $7 \%$ \\
\hline Circo & 1 & $7 \%$ \\
\hline
\end{tabular}




\begin{tabular}{|c|c|c|}
\hline Blogs & 1 & $7 \%$ \\
\hline Construtoras & 1 & $7 \%$ \\
\hline Total & 14 & $100 \%$ \\
\hline
\end{tabular}

Fonte: Elaborado pelos autores

\section{CONSIDERAÇÕES FINAIS}

Este estudo teve como objetivo identificar o perfil das principais correntes teóricas sobre alianças estratégicas e sua intensidade de publicações com aplicabilidade nas organizações brasileiras utilizando as pesquisas disponíveis na base de dados Scielo entre 2005 e 2015. A pesquisa bibliográfica explorou e descreveu o conteúdo constante em artigos publicados no idioma português. Utilizando o descritor "alianças estratégicas", identificou-se um total de 59 artigos publicados entre 2005 e 2015 dos quais 24 foram estudos aplicados em organizações. Deste total, 14 artigos foram base para este estudo onde 10 artigos foram excluídos, pois não estavam atendendo as áreas temáticas em ciências sociais e engenharias.

Os resultados da pesquisa demonstram que os estudos realizados referente alianças estratégicas tiveram como principal objetivo identificar e analisar os fatores motivadores e benefícios destas operações em organizações brasileiras. Os estudos realizados entre os anos de 2005 e 2015 são predominantemente compostas por dois autores e os métodos para coleta de dados identificados foram entrevistas e análise documental.

No período analisado (2005 a 2015) identificou-se que $21 \%$ dos artigos foram publicados no ano de 2007 e 14\% nos anos de 2011, 2013, 2014 e 2015, representando uma média de dois artigos por ano. Dente os estudos analisados identifica-se uma diversidade de formas de cooperação entre organizações no Brasil e que nos anos recentes existe uma continuidade de pesquisas sobre o tema considerando a sua importância estratégica e de sobrevivência para as organizações.

Quanto ao volume de publicações por periódicos identificou-se que as revistas com maior número de publicações são RAM - Revista de Administração Mackenzie, Gestão \& Produção, Cadernos EBAPE.BR e Revista de Administração Pública. São periódicos que abrem espaço para divulgação de pesquisas nas áreas temáticas de ciências sociais e engenharias com aplicabilidade em organizações.

Constatou-se a predominância de estudos organizacionais utilizando o estudo de caso como método de pesquisa. Este é um método que permite evidenciar a realidade contribuindo com o conhecimento dos fenômenos organizacionais, sendo comum entre as diversas áreas do conhecimento, mas principalmente ciências sociais e engenharias. Os estudos estão pressentes em diferentes segmentos organizacionais como petróleo, autopeças, metalurgia, tecnologia, aeronáutica, móveis, farmacêutico, hotelaria, circo, blogs e construtoras.

Conclui-se que alianças estratégicas é um tema atual e importante de ser analisado em diferentes segmentos organizacionais no Brasil. Com ênfase nesta temática de investigação, é possível ampliar os conhecimentos sobre o tema além de contribuir com diferentes fatores comportamentais, ambientais e aprendizado das organizações e pessoas. Como sugestão para pesquisas futuras propõe-se a ampliação de busca em outras bases de coleta de dados e outros idiomas. 


\title{
Analysis of publications profile on strategic alliances among organizations from 2005 to 2015
}

\begin{abstract}
The partnership strategies and strategic alliances between organizations are necessities of survival and business development process to the demands of the globalized market. The scientific advances and research on the subject strategic alliances becomes important to understand the practical studies in organizations. This study through literature aimed to identify the profile of scientific articles published in the Scielo database on strategic alliances in organizations, between the years 2005 and 2015. The research is characterized as a quantitative approach with exploratory objective and descriptive. Sampling was carried out considering the descriptor "strategic alliances" using document analysis and content analysis. From the research carried out in the database Scielo Brazil, we found a total of 59 articles on the subject of strategic alliances. Considering the analysis period, the language and the type of study of applicability in organizations, we analyzed a total of 24 articles. After reading, it was found that 14 articles could be the basis of this study.
\end{abstract}

Keywords: strategic alliances; companies; profile of articles.

\section{Referências}

AAKER, D.; KUMAR, D.; DAY, G. Pesquisa de Marketing. São Paulo: Atlas, 2001.

ABBADE, B. E. Análise de Alianças Estratégicas sob a ótica da Teoria dos Jogos. Revista de Administração da UNIMEP, v.7, n.3, p. 24-45, set /dez, 2009.

BARDIN, L. Análise de Conteúdo. 5ed. Lisboa: Edições 70, 2009.

CARTER, J.; CUSHIMAN, R.; HARTZ, S. The handbook of Joint Venture. Illinois, USA: Dover Jones-Irwin, 1988.

CERTO, S.; PETER, J. P. Administração Estratégica. 2‥ ed. São Paulo: Pearson Prentice Hall, 2005.

CHILD, J.; FAULKNER, D. Strategies of cooperation: Managing alliance, networks and joint ventures. Oxford: Oxford University Press, 1998.

De MAN, A. P. The network Economy: strategy, structure and management. Gloucester, UK: Elgar Publishing Ltd., 2004.

FAÇANHA, S. L. O. Aquisições, Fusões e Alianças Estratégicas na Configuração da Cadeia Sucroenergética Brasileira. 2012. 330 f. Tese (Doutorado em Administração) - Faculdade de Economia, Administração e Contabilidade, Universidade de São Paulo, São Paulo. 
FONSECA, J. J. S. Metodologia da pesquisa científica. Ceará: Universidade Estadual do Ceará, 2002.

GALERANI, J. Formação, estruturação e implementação de aliança estratégica entre empresas cooperativas. Revista Administração de Empresas [online]. v. 2, n. 1, Jan/Jun, 2003.

GIL, A. C. Como elaborar projetos de pesquisa. 4. ed. São Paulo: Atlas, 2002.

HAGEDOORN, J.; SHAKENRAAD, J. The effect of strategic technology alliances on company performance. Strategic Management Journal; Vol 15, 4; p. 291$309,1994$.

HITT, M. A.; IRELAND, R. D.; HOSKISSON, R. E. Administração Estratégica: competitividade e globalização. 2. ed. São Paulo: Cengage Learning, 2011.

KANTER, R. M. The art of alliances. Harvard Business Review, v. 72, n. 4, p. 96108, July-Aug.1994.

KLEIN, L.L.; Motivos que levam as empresas a retirarem-se dos processos cooperativos: contribuições para a formação, gestão e desenvolvimento de redes interorganizacionais. 2012. 183 f. Dissertação (Mestrado em Administração) - Universidade Federal de Santa Maria, Santa Maria, 2012.

LIMA, V. Z. et al. Perfil dos artigos sobre alianças estratégicas publicados na base de dados Scielo entre 2000 e 2014. Revista Brasileira de Gestão e Inovação. v. 2, n.3, p. 94-110, mai/ago, 2015.

LORANGE, P.; ROOS, J. Alianças estratégicas: formação, implementação e evolução. São Paulo: Atlas, 1996.

MATTANA, L.; NORO, G. B.; ESTRADA, R. Caracterização do processo de formação de alianças estratégicas. Internext - Revista Eletrônica de Negócios Internacionais, v. 3, n. 2, p. 181-198, ago./dez, 2008.

MORAN, M. R.; SOUZA, F. F. A.; BOAVENTURA, J. M. G.; MARINHO, B. L.; FISCHMANN, A. A. Alianças Estratégicas: uma análise bibliométrica da produção científica entre 1989 e 2008. Revista de Ciências da Administração, v. 12, n. 27, p. 42-62, 2010.

MINTZBERG, H.; AHLSTRAND, B.; LAMPEL, J. Safári de Estratégia. 2. ed. Porto Alegre: Bookman, 2010.

PORTER, M. E. Competição: estratégias competitivas essenciais. Rio de Janeiro: Elsevier, 1999.

RICHARDSON, R. J. Pesquisa social: métodos e técnicas. São Paulo: Atlas, 1999. 
ROSALEM, V. Formação e Gestão de Alianças Estratégicas na Cadeia Produtiva do Fumo. 2007. 278 f. Dissertação (Mestrado em Administração) Universidade Federal de Lavras, Minas Gerais.

RUMELT, R. Estratégia boa, estratégia ruim: descubra suas diferenças e importância. Rio de Janeiro: Elsevier, 2011.

SCIELO, Scientific Electronic Library Online. Disponível em: $<\mathrm{http}: / / w w w . s c i e l o . b r / s c i e l o . p h p ? s c r i p t=s c i \_h o m e \& l n g=p t \& n r m=i s o>$ Acesso em 25 jul. 2016.

SOUZA, D. B.; BALDIN, C. O papel das alianças estratégicas na competitividade das cooperativas de leite. Revista Organizações Rurais \& Agroindustriais, Lavras, v. 7, n. 3, p. 324-334, 2005.

TODEVA, E.; KNOKE, D. Strategic alliances and models of collaboration, Management Decision, v. 43, n. 1, p.123 - 148, 2005.

THOMPSON, A.; STRICKLAND A. Strategic Management, 12th ed. New York: McGraw-Hill, 2001.

VERGARA, S. C. Gestão de Pessoas. São Paulo: Atlas, 2009.

VERSCHOORE, J. R. et al. Concepções teóricas e verificações empíricas sobre a cooperação entre firmas no Brasil: uma introdução ao Fórum Alianças Estratégicas e Redes de Alianças. Revista de Administração Mackenzie, v. 15, n. 3, p. 14-20, 2014.

VOLPATO, Gildo. O Jogo e o Brinquedo: Reflexões a partir da Teoria Crítica. IN: Revista Educação e Sociedade, Campinas, vol. 23, n. 81, p. 217-226, dez. 2002.

WRIGHT, P.; KROLL, M. J.; PARNELL, J. Administração Estratégica: conceitos. São Paulo: Atlas, 2000.

YIN, R. K. Estudo de caso: planejamento e métodos. 5. ed. Porto Alegre: Bookman, 2015.

YOSHINO, M. Y.; RANGAN, U. S. Alianças estratégicas: Uma abordagem empresarial à globalização. São Paulo: Makron Books, 1996. 